\title{
Eosinophilic Esophagitis due to Gluten without Celiac Disease and Unusual Comorbidities
}

\author{
Gómez Torrijos Elisa ${ }^{*}$, Yesica Mendez Diaz ${ }^{1}$, Lucía Moreno Lozano $^{1}$, Alba M.Extremera Ortega ${ }^{1}$, \\ Joaquin Rodriguez Sanchez-Migallon², Jesus M.Borja Segade ${ }^{2}$, \\ José Fco Feo Brito ${ }^{1}$ and Rosa García Rodríguez ${ }^{1}$ \\ ${ }^{1}$ Allergology Service, Hospital General Universitario de Ciudad Real, Spain; ${ }^{2}$ Gastroenteriology Service, Hospital General Universitario \\ de Ciudad Real, Spain
}

\begin{abstract}
In recent years, it has become recognized that patients with eosinophilic esophagitis (EoE) have an increased risk of multiple autoimmune diseases. Possible shared genetic aetiologies have been observed between EoE and autoimmune diseases. Currently, it is believed that EoE is not associated with a higher risk of neoplasms since such published cases are very rare and there are only isolated reports. Herein, we describe a unique case of EoE due to gluten without coeliac disease. The patient presented some unusual comorbidities, such as hypothyroidism (autoimmune disease) and essential thrombocythemia (neoplasm of haematologic origin).
\end{abstract}

\begin{abstract}
Introduction
Polycythemia vera, essential thrombocythemia and myelofibrosis are clonal disorders collectively identified as myeloproliferative neoplasms. The incidence and prevalence rates of myeloproliferative neoplasms, in general, have increased in the last decade, ${ }^{1}$ as has eosinophilic esophagitis (EoE).,2,3 Moreover, studies of patients with EoE have uncovered an increased risk of multiple autoimmune diseases among this population. Possible shared genetic aetiologies have been observed between EoE and autoimmune diseases. Currently, however, it is believed that EoE is not associated with a higher risk of neoplasms, and this is primarily based on the fact that such published cases are very rare and there are only isolated reports in the medical literature. ${ }^{4}$
\end{abstract}

\section{Case report}

We report here the case of a 52-year-old male patient with a personal history of non-allergic bronchial asthma. He reported having

Keywords: Eosinophilic esophagitis; Gluten; Essential thrombocythemia; Autoimmune disease; Dysfagia

Abbreviations: 6FED, Six-food elimination diet; EoE, Eosinophilic esophagitis; Eos/cga, eosinophils/high power field.

Received: October 4, 2016; Revised: May 25, 2017; Accepted: May 26, 2017

*Correspondence to: Elisa Gomez Torrijos, Hospital General Universitario de Ciudad Real. C/ Obispo Rafael Torija s/n. 13005 Ciudad Real, Spain. Tel: 0034 626356825, 0034 926278000, ext 79556, E-mail: egomezt.cr@gmail.com

How to cite this article: Elisa GóT, Diaz YM, Lozano LíM, Ortega AME, SanchezMigallon JR, Segade JMB, Brito JéFF, Rodríguez RGí. Eosinophilic Esophagitis due to Gluten without Celiac Disease and Unusual Comorbidities. Exploratory Research and Hypothesis in Medicine 2017;2(2):41-42. doi: 10.14218/ERHM.2016. 00011 . experienced dysphagia with solid foods over the previous 9 years and isolated episodes of food impaction, which resolved spontaneously.

An esophagogastroduodenoscopy with biopsies was performed, and samples were obtained from each targeted organ and from the three sections of the oesophagus. More than 30 eosinophils/high power field (eos/hpf) were found in the upper, middle and lower oesophagus, but no eosinophils were detected in the stomach or duodenum. No atrophy of intestinal villi was observed in the duodenum.

After being treated with omeprazole ( $40 \mathrm{mgs}$ bid) for 2 months, a new oesophagoscopy was performed with biopsies using sections that detected $>20 \mathrm{eos} / \mathrm{hpf}$ in the three oesophageal sections analysed.

Skin prick tests and specific IgE tests for wheat, milk, egg, lentils, peanuts, hake and shrimp were all negative. The patient was therefore diagnosed with EoE and subsequently treated with a food elimination diet. We instructed the patient how to follow the six-food elimination diet (6FED) with slight modification: we removed all cereals (with and without gluten) for 6 weeks. After the diet, the EoE remitted ( 0 eos/hpf in the oesophageal biopsies). ${ }^{5}$ The eliminated foods were then introduced sequentially (one-byone), with biopsies performed at 6 weeks after the introduction of each food in order to detect the food responsible. The disease became reactivated only following the introduction of cereals. In order reduce the number of cereals to be excluded from the diet and to improve the patient's quality of life, we offered the patient a gluten-free diet that maintained the EoE in remission.

Three months later, the patient returned for a check-up and reported that he had lost $3 \mathrm{~kg}$ with the $6 \mathrm{FED}$, but had not regained the weight. He also reported eating all foods except those containing gluten. He made complaint of asthenia and a right upper quadrant abdominal pain that had lasted for 1 month. Blood test (Table 1) and chest/abdominal computed tomography scan were performed. 
Table 1. Blood tests made to the patient

\begin{tabular}{ll}
\hline Items & Results \\
\hline Blood & 605,000 platelets/mcL \\
RBC and WBC counts & Normal \\
Coagulation & Normal \\
Except fibrinogen & $775 \mathrm{mg} / \mathrm{mL}$ \\
ESR & $40 \mathrm{~mm}$ \\
Lupus anticoagulant & Positive \\
GGT & $262 \mathrm{U} / \mathrm{L}$ \\
LDH & $700 \mathrm{U} / \mathrm{L}$ \\
Alkaline phosphatase & $259 \mathrm{U} / \mathrm{L}$ \\
Tyroid Tests & TSH:1.26 mcu/ml; T4:N \\
Antibodies of connective tissue diseases & All Negative \\
\hline
\end{tabular}

The computed tomography scan showed hepatosplenomegaly and pleural effusion with atelectasis of the lower lobe of the left lung due to ischaemia and left portal vein thrombosis. The patient was admitted and given a final diagnosis of chronic myeloproliferative syndrome, of the essential thrombocytopenia type (JAK2-positive, calreticulin-negative), and deemed at high risk of thrombosis and hypothyroidism.

\section{Discussion}

Our patient suffered from classic EoE, very similar to the cases previously described (male, onset of symptoms in the 4th decade of life). ${ }^{6}$ In our patient, the EoE did not subside with high doses of IBPs, and, after explaining to him the possible treatments (corticosteroids or diet), he chose the elimination diet. ${ }^{7}$ Since results of allergy testing against the most frequently involved foods were negative, the patient was prescribed a 6 FED. ${ }^{5}$ In order to improve the quality of life of the patient, we followed what other authors have done with other foods, such as milk, ${ }^{8}$ and offered him the opportunity to test whether gluten was responsible for his EoE.

The patient agreed to adhere to the same diet as if he were a patient with coeliac disease. After performing oesophagoscopy, we found that gluten was the responsible protein for the patient's EoE. Therefore, even if he had to follow the diet indefinitely, he could eat rice and corn and gluten-free cereals, for which many supermarkets have wide selections of currently. Although in this patient, gluten produced an eosinophilic inflammation of the oesophagus, it did not produce inflammation of the stomach or duodenum; in addition, we ruled out coeliac disease in this patient, as villous atrophy was not detected in the duodenal biopsies.

We know from our experience that when patients adhere to the 6FED diet they lose at least $2-3 \mathrm{~kg}$ in 6 weeks, but this weight is quickly recovered. In this patient, however, this did not happen and, instead, he complained of other symptoms. The subsequent studies showed at least one autoimmune disease (hypothyroidism), an increasingly common finding in patients with EoE. ${ }^{9}$ Our patient also had developed an associated haematologic malignancy, which is rare in patients with EoE. We have reviewed the literature and only found isolated cases of EoE as a paraneoplastic syndrome. These include a patient with ganglioneuroblastoma and another case of an oesophageal tumour compatible with the "classical variant" of inflammatory myofibroblastic tumour, with prominent eosinophilic infiltrate from the lesional to the extralesional area consistent with EoE. ${ }^{4,10}$ We believe that patients with EoE have a risk of developing malignancies similar to that in the general population.

In conclusion, this is the first report of a case of EoE due to gluten without coeliac disease that presents the unusual comorbidities of hypothyroidism (an autoimmune disease) and essential thrombocythemia (a neoplasm of haematologic origin).

\section{Conflict of interest}

The authors have no conflict of interests related to this publication.

\section{Author contributions}

Study concept and design (JRS), acquisition of data (YMD, LML, AEO), analysis and interpretation of data (JMS), drafting of the initial and final manuscript (JFFB), critical revision of the manuscript (RGR), study supervision (EGT), translation to English (YMD, LML, AEO).

\section{References}

[1] Roaldsnes C, Holst R, Frederiksen H, Ghanima W. Myeloproliferative neoplasms: trends in incidence, prevalence and survival in Norway. Eur J Haematol 2017;98(1):85-93. doi:10.1111/ejh.12788.

[2] Spergel JM. An allergist's perspective to the evaluation of Eosinophilic Esophagitis. Best Pract Res Clin Gastroenterol 2015;29(5):771-781. doi:10.1016/j.bpg.2015.06.011.

[3] Mansoor E, Cooper GS. The 2010-2015 Prevalence of Eosinophilic Esophagitis in the USA: A Population-Based Study. Dig Dis Sci 2016;61(10):2928-2934. doi:10.1007/s10620-016-4204-4.

[4] Prader S, Spalinger J, Caduff J, Hürlimann S, Rischewski J. Eosinophilic esophagitis as paraneoplastic syndrome in a patient with ganglioneuroblastoma. Klin Padiatr 2015;227(3):173-175. doi:10.1055 /s-0035-1547307.

[5] Lucendo AJ, Arias Á, González-Cervera J, Yagüe-Compadre JL, Guagnozzi D, Angueira T, et al. Empiric 6-food elimination diet induced and maintained prolonged remission in patients with adult eosinophilic esophagitis: a prospective study on the food cause of the disease. J Allergy Clin Immunol 2013;131(3):797-804. doi:10.1016/j. jaci.2012.12.664.

[6] Castro Jiménez A, Gómez Torrijos E, García Rodríguez R, Feo Brito F, Borja Segade J, Galindo Bonilla PA, et al. Demographic, clinical and allergological characteristics of Eosinophilic Esophagitis in a Spanish central region. Allergol Immunopathol (Madr) 2014;42(5):407-414. doi:10.1016/j.aller.2013.04.004.

[7] Dellon ES, Gonsalves N, Hirano I, Furuta GT, Liacouras CA, Katzka DA et al. ACG clinical guideline: Evidenced based approach to the diagnosis and management of esophageal eosinophilia and eosinophilic esophagitis (EoE). Am J Gastroenterol 2013;108(5):679-692; quiz 693. doi:10.1038/ajg.2013.71.

[8] Leung J, Hundal NV, Katz AJ, Shreffler WG, Yuan Q, Butterworth CA, et al. Tolerance of baked milk in patients with cow's milk-mediated eosinophilic esophagitis. J Allergy Clin Immunol 2013;132(5):12151216.e1. doi:10.1016/j.jaci.2013.08.017.

[9] Lecouffe-Desprets M, Groh M, Bour B, Le Jeunne C, Puéchal X. Eosinophilic gastrointestinal disorders associated with autoimmune connective tissue disease. Joint Bone Spine 2016;83(5):479-484. doi:10.1016/j.jbspin.2015.11.006.

[10] Fassan M, Castoro C, Saenz AJ, Cagol M, Ninfo V, Rugge M. Inflammatory myofibroblastic tumor as adverse outcome of eosinophilic esophagitis. Endoscopy 2009;41(Suppl2):E95-E96. doi:10.1055/s-20081077646. 